\title{
The role of adherence in tuberculosis HIV-positive patients treated in ambulatory regimen
}

\author{
M. Rocha*, S. Pereira*, L. Ferreira*, H. Barros ${ }^{\#}$
}

The role of adherence in tuberculosis HIV-positive patients treated in ambulatory regimen. M. Rocha, S. Pereira, L. Ferreira, H. Barros. (C) ERS Journals Ltd 2003. ABSTRACT: Adherence to antituberculosis treatment, a major determinant of outcome, is of special concern in human immunodeficiency virus (HIV)-positive patients. However, tuberculosis death in HIV-positive patients remains higher than in HIV-negative patients, regardless of adherence.

To assess determinants for an unfavourable tuberculosis outcome (defined as no cure or death), and determinants for nonadherence to antituberculosis treatment, 70 HIVpositive patients with tuberculosis referred to an outpatient centre were studied. Patient outcome was compared according to HIV risk factors, other opportunistic diseases, antiretroviral drugs use, current $i . v$. drugs use, a methadone programme participation, tuberculosis features, treatment characteristics and adherence. Adherent and nonadherent patient characteristics were also compared.

An unfavourable outcome occurred in $22.9 \%$ of patients and $32.9 \%$ were nonadherent with therapy. Nonadherence was the only independent determinant for an unfavourable outcome. Adherence was independently associated with current $i$.v. drug use, treatment complications and use of methadone.

This study confirms that human immunodeficiency virus-infected patients, treated as outpatients, have high rates of nonadherence and that adherence is the strongest determinant for tuberculosis outcome. Independently of the current use of drugs, a methadone programme improves adherence to treatment.

Eur Respir J 2003; 21: 785-788.
*Centre for Respiratory Diseases Diagnosis, Constituição and ${ }^{\#}$ Dept of Hygiene and Epidemiology, University of Porto Medical School, Porto, Portugal.

Correspondence: S. Pereira

Dept of Hygiene and Epidemiology

University of Porto Medical School

4200 - Porto

Portugal

Fax: 351225095618

E-mail: epimed@med.up.pt

Keywords: Adherence

human immunodeficiency virus

methadone

outcome

tuberculosis

Received: September 202002

Accepted after revision: December 202002
After a declining trend, tuberculosis re-emerged worldwide as an important cause of morbidity and mortality in the mid 1980 s and 1990s. This epidemiological change has been largely attributed to the growing human immunodeficiency virus (HIV) epidemic [1-7]. Associated with the increasing number of co-infected patients, multidrug resistant (MDR) tuberculosis has increased and spread, not only to those infected with HIV, but to the entire community [3, 4, 8, 9]. The lack of adherence to therapy is the major factor associated with relapses of tuberculosis and emergence of MDR strains [4, 5, 9-12]. Directly observed treatment (DOT), though improving, has not eliminated the problem of nonadherence $[4,8-10,13,14]$. However, even during active treatment, death related to tuberculosis is greater in HIVpositive than in HIV-negative patients [1, 11, 15, 16].

The aims of this study were to identify the determinants of an unfavourable outcome (no cure or death) and the determinants for nonadherence to treatment in HIV-infected patients with tuberculosis, treated as outpatients in a DOT regimen, in a setting where tuberculosis rates remain the highest in Europe [17].

\section{Participants and methods}

The study included 70 HIV (serotype 1)-infected patients with tuberculosis, $62(88.6 \%)$ male and eight (11.4\%) female, consecutively referred to a centre for ambulatory treatment of respiratory diseases (CDP-Constituição, Porto, Portugal), between January 1995-December 1996, where DOT treatment is used. Treatment was observed daily during weekdays and drugs were provided without supervision for the weekends. All patients were referred with a tuberculosis diagnosis from general hospitals in Porto, in most cases after treatment was initiated. Antiretroviral treatment was prescribed by a hospital consultant of infectious diseases. Medication was delivered at the hospital free of charge and there was no direct observed treatment policy. Patients' age ranged 20-49 yrs (mean $\pm \mathrm{sD}, 31.8 \pm 6.36)$. Sixty patients $(85.7 \%)$ were i.v. drug abusers and the remaining 10 patients $(14.3 \%)$ presented multiple unprotected sexual contacts, both high-risk factors for HIV. Drug abusers, in comparison to patients with sexual risk, were more frequently male $(90.0 \%$ versus $80.0 \%$; $\mathrm{p}=0.320)$ and of younger age (31.1 versus $36.1 \mathrm{yrs} ; \mathrm{p}=0.062)$. For those patients whose risk was drug abuse, factors recorded included: if subjects were currently users of $i$. v. drugs, if subjects were in a programme of methadone, and if therapy with methadone was performed with (in CDP) or without (in other clinics) antituberculosis drugs. The dose of methadone was adjusted according to patients' symptoms. The diagnosis of tuberculosis was confirmed by bacteriological analysis (stained smear and/or culture) in 59 patients and by histopathological examination in six patients. In the remaining five $(7.1 \%)$ patients the diagnosis was presumed, based on clinical and radiological criteria, and an appropriate response to treatment.

According to the helper cell (CD4) count the authors defined two groups: $<200 \mathrm{~mm}^{3}$ or $\geqslant 200 \mathrm{~mm}^{3}$. The presence of other opportunistic diseases, the use of antiretroviral drugs and the results of sensitivity tests were recorded. MDR tuberculosis was defined as the presence of resistance to both isoniazid (Zimaia, Lisbon, Portugal) and rifampicin (Le Petit, Anagni, Italy). Patients were grouped as either pulmonary or 
extra-pulmonary tuberculosis sufferers, the latter may also include pulmonary disease. Chest radiographs were classified as typical (usual patterns of reactivation of adult disease, namely cavitation and upper lobe disease) or atypical (characteristic patterns of primary disease or normal radiographs). The antituberculosis treatment was a standard or a modified scheme, the later meaning the substitution or association of other drugs to the standard treatment [7]. Treatments were scheduled for $\geqslant 9$ months, if no response was achieved after that time. Previous tuberculosis treatment, the occurrence of complications related to present antituberculosis treatment and treatment adherence (positive, if less than two missing visits per week), were also recorded. According to the outcome, patients were divided into two groups; those who cured tuberculosis (favourable clinical outcome and/or negative stain smear), and those who did not or died from tuberculosis as stated in death certificates. All deaths from tuberculosis occurred at hospital and patients had MDR tuberculosis or died during the first 2 months of antituberculosis treatment, without any negative stain smear.

In data analysis, an unpaired t-test or Mann-Whitney U-test were used for continuous variables, according to the sample type of distribution. Proportions were compared with the Chi-squared test, using the Yates correction or the Fisher exact test, as indicated. The strength of associations was estimated by means of odds ratios (OR) and respective $95 \%$ confidence intervals (CI). Logistic regression was used to calculate adjusted odds ratios, including in the model all variables that presented a probability test $<0.150$ in the univariate analysis.

\section{Results}

During or at the end of antituberculosis treatment, 16 $(22.9 \%)$ patients presented an unfavourable outcome; six showed no cure and 10 died from tuberculosis. No significant difference for outcome was found according to sex, age or risk group (table 1). No cure or death was associated with a CD4 $<200 \quad(\mathrm{OR}=5.19 ; 95 \%$; CI: 0.96-37.3). Forty-six patients $(65.7 \%)$ had associated illnesses. There were no differences between those who were cured and those who were not, according to the presence of other illnesses. For $49(70.0 \%)$ patients, nucleoside analogous drugs were prescribed, with protease inhibitors additionally prescribed to eight $(11.4 \%)$ of these, but only $36(51.4 \%)$ and seven $(10.0 \%)$ actually took the nucleoside analogous and protease inhibitors, respectively. The use of nucleoside analogous drugs was inversely associated with no cure or death from tuberculosis $(\mathrm{OR}=0.23 ; 95 \%$ CI: 0.05-0.92). No significant association was found for the use of protease inhibitors. From the 60 patients with a drug abuse history, $18(30.0 \%)$ were still current i.v. drug abusers. Current drug abusers more frequently had an unfavourable outcome (OR=2.50; 95\% CI: 0.58-10.82).

For the 56 patients in which a sensitivity test was carried out, seven $(12.5 \%)$ presented MDR strains. The presence of resistance was higher in those who were not cured or died $(\mathrm{OR}=4.61$; 95\% CI: 0.70-32.25). Four (5.7\%) patients had been treated for tuberculosis, three of them presenting a sensitivity test with no MDR strains. All four patients with previous tuberculosis treatment cured the present disease.

Extra-pulmonary tuberculosis occured similarly in cured and uncured patients (table 1). Patients with an unfavourable outcome more frequently had an atypical chest radiograph $(\mathrm{OR}=5.19 ; 95 \% \mathrm{CI}$ : 0.96-37.29). A modified treatment was used in $13(18.6 \%)$ patients. All but one had complications related to antituberculosis treatment (five patients), isolation of a MDR strain (four patients) or both (three patients).
Table 1.-Clinical outcome according to clinical, bacteriological and radiological features, type of tuberculosis, and treatment characteristics in 70 tuberculosis human immunodeficiency virus-infected patients

$\begin{array}{ll}\text { Cure } & \begin{array}{l}\text { No cure } \\ \text { or death }\end{array} \text { OR p-value }\end{array}$

\begin{tabular}{|c|c|c|c|c|}
\hline Sex (male) & $50(92.6 \%)$ & $12(75.0 \%)$ & 0.2 & 0.074 \\
\hline $\mathrm{Age}^{\#}$ yrs & $31.9 \pm 6.1$ & $31.5 \pm 7.2$ & & 0.823 \\
\hline Drug addiction & $47(87.0 \%)$ & $13(81.3 \%)$ & 0.7 & 0.685 \\
\hline CD4 $<200$ & $31(57.4 \%)$ & $14(87.5 \%)$ & 5.2 & 0.056 \\
\hline Presence of other illness & $35(64.8 \%)$ & $11(68.8 \%)$ & 1.2 & 0.993 \\
\hline $\begin{array}{l}\text { Use of nucleoside } \\
\text { analogous }\end{array}$ & $32(59.3 \%)$ & $4(25.0 \%)$ & 0.2 & 0.034 \\
\hline $\begin{array}{l}\text { Use of protease } \\
\text { inhibitors }\end{array}$ & $5(9.3 \%)$ & $2(12.5 \%)$ & 1.4 & 0.655 \\
\hline Current i.v. drug use & $12(25.5 \%)$ & $6(46.2 \%)$ & 2.5 & 0.181 \\
\hline Multidrug resistance $^{+}$ & $3(7.3 \%)$ & $4(26.7 \%)$ & 4.6 & 0.074 \\
\hline $\begin{array}{l}\text { Extrapulmonary } \\
\text { tuberculosis }\end{array}$ & $23(42.6 \%)$ & $6(37.5 \%)$ & 0.8 & 0.941 \\
\hline $\begin{array}{l}\text { Atypical chest } \\
\text { radiograph }^{\S}\end{array}$ & $31(57.4 \%)$ & $14(87.5 \%)$ & 5.2 & 0.056 \\
\hline Modified treatment & $7(13.0 \%)$ & $6(37.5 \%)$ & 4.0 & 0.060 \\
\hline Complications & $7(13.0 \%)$ & $11(68.8 \%)$ & 14.8 & $<0.001$ \\
\hline Nonadherence & $9(16.7 \%)$ & $14(87.5 \%)$ & 35.0 & $<0.001$ \\
\hline
\end{tabular}

Data are presented as $\mathrm{n}(\%)$, unless otherwise stated. OR: odds ratio; CD4: helper cell count; i.v.: intravenous; ${ }^{\#}$ : mean $\pm \mathrm{SD} ;{ }^{\text {": }}$ data for the 60 patients in whom risk was drug addiction; ${ }^{+}$: includes only the 56 patients where a sensitivity test to drugs had been carried out; $\$$ : includes both pulmonary and extrapulmonary tuberculosis.

Treatment complications occurred in 18 (25.7\%) patients; toxic hepatitis in 12, gastrointestinal intolerance in four and rash in two. In patients where an unfavourable outcome occurred, the use of a modified treatment was more frequent $(\mathrm{OR}=4.03$; 95\% CI: $0.93-17.85)$, as was the presence of treatment complications (OR=14.77; 95\% CI: 3.32-71.64) and no treatment adherence $(\mathrm{OR}=35.0 ; 95 \% \mathrm{CI}$ : 5.80-276.4).

In a multivariate model, only nonadherence to antituberculosis treatment remained significantly associated with an unfavourable outcome (table 2).

Relative to adherence, $23(32.9 \%)$ patients were nonadherent to antituberculosis treatment; two of them abandoning it after 2 months of therapy, the remaining 21 having irregular treatments. Adherence was similar with sex, age or HIV group risk. The presence of other opportunistic diseases was also similar between nonadherent and adherent patients (table 3).

Table 2. - Multivariate analysis of determinants of no recovery from tuberculosis in human immunodeficiency virus-positive patients

\begin{tabular}{lcl}
\hline & OR & $95 \%$ CI \\
\hline Sex (male) & 2.1 & $0.09-47.93$ \\
CD4 <200 & 5.1 & $0.41-63.09$ \\
Use of nucleoside analogous & 0.5 & $0.06-4.78$ \\
Sensitivity test & & \\
$\quad$ Multidrug resistance & 11.1 & $0.15-797.1$ \\
$\quad$ Not assessed & 0.1 & $0.00-3.19$ \\
Atypical chest radiograph & 7.2 & $0.43-119.1$ \\
Modified treatment & 0.3 & $0.00-11.75$ \\
Treatment complications & 7.4 & $0.73-75.97$ \\
Nonadherence & 29.2 & $2.43-350.1$ \\
\hline
\end{tabular}

OR: odds ratio; CI: confidence interval; CD4: helper cell count. \#: in comparison with no multidrug resistance. 
Table 3. - Nonadherence according to clinical, bacteriological and radiological features, type of tuberculosis, and treatment characteristics in 70 tuberculosis human immunodeficiency virus-infected patients

\begin{tabular}{|c|c|c|c|c|}
\hline & Adherence & Nonadherence & OR & $\mathrm{p}$-value \\
\hline Sex (male) & $44(93.6 \%)$ & $18(78.3 \%)$ & 0.3 & 0.104 \\
\hline $\mathrm{Age}^{\#}$ yrs & $32.4 \pm 6.3$ & $30.6 \pm 6.3$ & & 0.270 \\
\hline Drug addiction & $39(83.0 \%)$ & $21(91.3 \%)$ & 2.1 & 0.480 \\
\hline $\begin{array}{l}\text { Presence of other } \\
\text { illness }\end{array}$ & $30(63.8 \%)$ & $16(69.6 \%)$ & 1.3 & 0.836 \\
\hline $\begin{array}{l}\text { Use of nucleoside } \\
\text { analogous }\end{array}$ & $30(63.8 \%)$ & $6(26.1 \%)$ & 0.2 & 0.007 \\
\hline $\begin{array}{l}\text { Use of protease } \\
\text { inhibitors }\end{array}$ & $5(10.6 \%)$ & $2(8.7 \%)$ & 0.8 & 0.995 \\
\hline $\begin{array}{l}\text { Current i.v. drug use } \\
\text { Methadone }^{+}\end{array}$ & $4(10.3 \%)$ & $14(66.7 \%)$ & 17.5 & $<0.001$ \\
\hline In CDP & $7(19.4 \%)$ & $0(0.0 \%)$ & 0.00 & 0.082 \\
\hline Other cli & $3(9.4 \%)$ & 2( & 1.0 & 0.995 \\
\hline Multidrug r & $3(8.3$ & $4(2$ & 2.7 & 0.234 \\
\hline $\begin{array}{l}\text { Previous tuberculosis } \\
\text { therapy }\end{array}$ & $2(4.3 \%)$ & $2(8.7 \%)$ & 2.1 & 0.593 \\
\hline Modified treatment & 0 & & 3.0 & 0.103 \\
\hline Complications & $5(10.6 \%)$ & $13(56.5 \%)$ & 10.9 & $<0.001$ \\
\hline
\end{tabular}

Data are presented as n (\%), unless otherwise stated; OR: odds ratio; i.v.: intravenous; CPD: centre for ambulatory treatment of respiratory diseases; ${ }^{\#}$ : mean \pm SD; ${ }^{\text {? }}$ : data for the 60 patients in whom the risk was drug addiction; ${ }^{+}$: in comparison with no use of methadone; \$: includes only the 56 patients in which a sensibility test to drugs had been carried out.

Current use of nucleoside analogous drugs was significantly less frequent $(\mathrm{OR}=0.20 ; 95 \% \mathrm{CI}$ : $0.06-0.69)$ in nonadherent patients, but no significant association was found with the use of protease inhibitors (table 3 ).

Current $i$.v. drug users were more frequently nonadherent than those which were not $(\mathrm{OR}=17.50 ; 95 \% \mathrm{CI}$ : 3.72-91.90). Twelve $(20.0 \%)$ drug abusers were in a methadone programme; seven of them given methadone with antituberculosis treatment and five without. All patients given methadone together with antituberculosis drugs in the same clinical setting were adherent (table 3 ).

No significant difference was found between adherent and nonadherent patients for the presence of MDR tuberculosis, the use of a modified treatment and a previous antituberculosis treatment. The presence of treatment complications was significantly more frequent in nonadherent patients $(\mathrm{OR}=10.92$; 95\% CI: $2.71-47.00)$.

In a multivariate model, current $i$.v. drug use and occurrence of complications related to treatment were independent factors associated with nonadherence. Use of methadone (either with or without antituberculosis drugs) was independently and inversely associated with nonadherence (table 4).

Table 4. - Multivariate analysis of determinants for nonadherence to antituberculosis treatment

\begin{tabular}{lcl}
\hline & OR & $95 \%$ CI \\
\hline Sex (male) & 0.02 & $0.00-1.25$ \\
Use of nucleoside analogous & 0.1 & $0.02-1.30$ \\
Current $i . v$. drug use & 56.6 & $5.41-592.0$ \\
Use of methadone & 0.005 & $0.00-0.40$ \\
Modified treatment & 9.1 & $0.74-110.3$ \\
Therapy complications & 12.1 & $1.42-103.1$ \\
\hline
\end{tabular}

OR: odds ratio; $\mathrm{CI}$ : confidence interval; i.v.: intravenous.

\section{Discussion}

The HIV epidemic has greatly altered the epidemiological course of tuberculosis $[6,11]$. In areas of higher prevalence of latent tuberculosis the disease constitutes one of the most important opportunistic infections in HIV-positive patients [2]. Compared to other European countries, Portugal presents higher tuberculosis rates [17]. HIV infection has also been steadily increasing since the mid 1980s. In Portugal until September 1998, 57\% of prevalent HIV-infected cases had tuberculosis, a higher figure than other developed countries [18].

HIV and Mycobacterium tuberculosis co-infection is associated with a higher mortality $[1,11,15,16]$, although most deaths in those who receive an effective therapy are due to complications of HIV infection rather than tuberculosis [11]. In the current study, almost one-quarter of patients do not recover from tuberculosis. The mortality was $14.3 \%$, much higher than the $4.7 \%$ for the global fatality rate of tuberculosis in Portugal [19]. Immunosuppression associated with HIV infection contributes to the development of tuberculosis $[2,7,11]$. In the current study, no association between the level of CD4, presence of other associated diseases or the use of antiretroviral drugs and clinical outcome was found. Multidrug resistance was $12.5 \%$, a figure similar to that found in a study with a similar population in Texas [20]. Other studies have shown that HIV infection was not a risk factor for MDR tuberculosis $[1,20]$, but that there is a higher rate of MDR tuberculosis in HIV-infected patients, either because of a failure of tuberculosis control or because immunosuppression facilitates the rapid spread of MDR strains $[1,4,8,11$, 20]. In the current study, MDR tuberculosis was more frequent in patients who did not recover. The failure to find it as a statistically significant determinant for clinical outcome may be due to lack of power.

Tuberculosis presents with particular features in HIVpositive patients, namely a greater preponderance for extrapulmonary disease $[3,5,6,11,16]$ and the presence of atypical features in chest radiographs $[5,7,11,16]$, which may cause difficulties and delay the diagnosis. In the population included in the current study, $41.4 \%$ had extrapulmonary disease. It was suggested that some groups had an increased risk of extrapulmonary disease, for example injecting drug users and young patients living in areas with high rates of tuberculosis, such as Portugal [3]. No association between this form of tuberculosis and clinical outcome was found, in contrast to a previous study showing an association, though weak, with recovery [2]. The proportion of patients experiencing antituberculosis treatment complications was $25.7 \%$, which is in accordance with the increased risk for adverse reactions in HIV-infected patients [5, 11]. Complications and presentation with an atypical chest radiograph was more frequent in patients which were not cured of, or died from, tuberculosis. After adjustment for other variables, these did not constitute independent determinants for nonrecovery of tuberculosis, possibly reflecting a lack of power. In particular, it is unlikely that the association between an atypical chest radiograph and outcome can be confounded by adherence. However, data from the current study supports nonadherence as the strongest determinant for poor outcome of tuberculosis in HIV-infected outpatients.

The proportion of nonadherence was $32.9 \%$. Nonadherence has been associated with relapses of tuberculosis and emergence of MDR strains [4-6, 8, 9, 11, 12], thus is of special concern to HIV-positive patients given their increased susceptibility to tuberculosis $[1-4,9,11]$. In the current study, after adjustment for other variables, the authors could find no association between MDR tuberculosis or current 
use of antiretroviral drugs and antituberculosis treatment adherence.

Most patients in the current study were i.v. drug abusers, a group considered to be at higher risk to both HIV infection and tuberculosis, as well as a group in which nonadherence is a major concern $[4,9,10]$. Although nonadherence is a frequent and important problem, it is largely unpredictable, depending on the patient population and control programmes. However, there are groups with more commonly reported nonadherence, such as the homeless and i.v. drug users [12]. In the sample from the current study, a history of drug abuse compared to sexual risk was not associated with a poor prognosis or with higher rates of nonadherence, though current use of i.v. drugs was an independent determinant for nonadherence. Treatment complications and no methadone use were also independent determinants for nonadherence. The dose of methadone seems important for the retention of subjects in treatment programmes, with even low doses $(20 \mathrm{mg})$ superior to nonmaintenance detoxification treatment, while moderate (40-50 mg) and particularly high (80-100 mg) daily doses associated with greater retention in treatment programmes $[21,22]$. In the authors' setting, the policy was to initiate treatment with $40-80 \mathrm{mg}$ of methadone, according to the usual level of drug consumed, and then adjust this according to patient's symptoms.

In conclusion, the current study confirms that adherence to antituberculosis treatment is the strongest independent determinant for recovery of tuberculosis in HIV-positive patients and shows that the institution of a programme for substitution of drugs with methadone (either with or without antituberculosis drugs), independently of the current drug abuse, increases adherence. It has been suggested that in patients at higher risk for nonadherence, more aggressive forms of treatment, even if necessary with hospitalisation, should be promoted. However, coercive hospitalisation has legal and ethical restraints, so its use should be limited [23, 24]. In different populations, DOT has partly solved the problem of antituberculosis treatment adherence and the association of incentives, such as food, clothes, bus tickets, help to improve adherence $[4,6-9,11,13,14]$.

As previously shown $[10,23,24]$ and confirmed in the setting of the current study, a methadone programme has a clear impact in improving the prognosis of tuberculosis in human immunodeficiency virus-infected drug abusers, further preventing the spread of the disease to the whole community.

\section{References}

1. Grange JM. Epidemiology and control of mycobacterial disease. In: Mycobacteria and Human Disease. 2nd edn. Oxford, Oxford University Press, 1996; pp. 117-137.

2. Sudre P, Hirschel BJ, Gatell JM, et al. Tuberculosis among European patients with the acquired immune deficiency syndrome. Tuber Lung Dis 1996; 77: 322-328.

3. Schwoebel V, Delmas MC, Ancelle-Park RA, Brunet JB. Factors associated with extrapulmonary tuberculosis as an AIDS-defining disease in Europe. Tuber Lung Dis 1995; 76: 281-285.
4. Remington J, Hollingworth GR. New tuberculosis epidemic. Can Fam Physician 1995; 41: 1014-1023.

5. Fitzgerald JM. Tuberculosis in the 1990s. Can Fam Physician 1995; 41: 1030-1036.

6. Cantwell MF, Snider DE, Cauthen GM, Onorato IM Epidemiology of tuberculosis in the United States, 1985 through 1992. JAMA 1994; 272: 535-539.

7. U.S. Department of Health and Human Services, Centers for Disease Control and Prevention. Core Curriculum on Tuberculosis. What the clinician should know. 4th Edn. Atlanta, GA, USA, 2000.

8. Bastian I, Colebunders R. Treatment and prevention of multidrug-resistant tuberculosis. Drugs 1999; 58: 633-661.

9. Schneider RF, Rosen MJ. Respiratory infections in patients with HIV infection. Curr Opin Pulm Med 1996; 2: 246-252.

10. Gourevitch MN, Wasserman W, Panero MS, Selwyn PA. Successful adherence to observed prophylaxis and treatment of tuberculosis among drug users in a methadone program. J Addict Dis 1996; 15: 93-104.

11. Havlir DV, Barnes PF. Tuberculosis in patients with human immunodeficiency virus infection. N Engl J Med 1999; 340: 367-373.

12. Pablos-Méndez A, Knirsch CA, Barr G, Lerner BH, Frieden TR. Nonadherence in tuberculosis treatment: predictors and consequences in New York City. Am J Med 1997; 102: 164-170.

13. Smirnoff M, Goldberg R, Indyk L, Adler JJ. Directly observed therapy in an inner city hospital. Int J Tuberc Lung Dis 1998; 2: 134-139.

14. Norval PY, San KK, Bakhim T, Rith DN, Ahn DI, Blanc L. DOTS in Cambodia. Directly observed treatment with shortcourse chemotherapy. Inter J Tuberc Lung Dis 1998; 2: 4451 .

15. Borgdorff MW, Veen J, Kalisvaart NA, Nagelkerke N. Mortality among tuberculosis patients in The Netherlands in the period 1993-1995. Eur Respir J 1996; 11: 816-820.

16. Rabaud C, Engozogho M, Dailloux M, Hoen B, May T, Canton P. Tuberculosis in Lorraine, France: study of prognostic factors. Int J Tuberc Lung Dis 1997; 1: 246-249.

17. The Computerized Information System for Infectious Diseases. World Health Organization Regional Office for Europe. Number of tuberculosis cases notified. http://www. cisid.who.dk/tb/TBProfile.asp. Accessed and last updated November 11, 2002.

18. National Institute of Health. AIDS: The Portuguese situation - June 1998. Lisboa, Portugal, National Institute of Health, 1998. pp. 5-7.

19. National Institute of Statistics (INE). Estatísticas da Saúde 1994. Lisboa. Portugal, National Institute of Statistics, 1995. p. 180.

20. Spellman CW, Matty KJ, Weis SE. A survey of drugresistant Mycobacterium tuberculosis and its relationship to HIV infection. AIDS 1998; 12: 191-195.

21. Fiellin DA, O'Connor PG. Office-based treatment of opioiddependent patients. $N$ Engl J Med 2002; 347: 817-823.

22. Strain EC, Bigelow GE, Liebson IA, Stitzer ML. Moderatevs high-dose methadone in the treatment of opioid dependence. JAMA 1999; 281: 1000-1005.

23. Gasner MR, Maw KL, Feldman GE, Fujiwara PI, Frieden TR. The use of legal action in New York City to ensure treatment of tuberculosis. N Engl J Med 1999; 340: 359-366.

24. Campion EW. Liberty and the control of tuberculosis. $N$ Engl J Med 1999; 340: 385-386. 